\title{
AN OVERVIEW OF CRITICAL SUCCESS FACTORS FOR IMPLEMENTING 3D PRINTING TECHNOLOGY IN MANUFACTURING FIRMS
}

\author{
Nurhalida Shahrubudin, Lee Te Chuan*, Rohaizan Ramlan \\ Universiti Tun Hussein Onn Malaysia, Malaysia
}

Additive manufacturing, also known as $3 D$ printing or digital fabrication technology, is a process of accumulating deposited layers to form solid $3 D$ objects from 3D models in digital files. 3D printing technology is a fast-emerging technology. Nowadays, 3D printing technology is successfully applied in shaping the globe and producing most of the products used today, from simple plastics to advanced ceramics and metallics. 3D printing technology can print an object layer by layer, by directly depositing the material using computer software, with only just one click. This paper gives an overview of the Critical Success Factors (CSFs) for 3D printing technology in manufacturing firms. The literature found in this paper is mainly from Emerald Insight, Science Direct, Google Scholar and Additive Manufacturing. Briefly, the list of Critical Success Factors can be divided into nine major factors, which are cost, technology, business and support, management and organisation, materials, quality and accuracy, demand, the environment and lastly, research and development.

Key words: Additive manufacturing, Digital fabrication, Implementation, Layers, Manufacturing technology.

\section{INTRODUCTION}

3D printing technology has been successfully practiced in shaping the world and producing most of the products used today, from simple plastics to advanced ceramics, metals, and composites. 3D printing technology, also known as Additive Manufacturing (AM), has become a common term referring to a wide-ranging group of $3 \mathrm{D}$ printing machines that operate on the principle of producing objects from the bottom-up and layer by layer to build 3D objects [1].

Nowadays, 3D printing technology is used for limitless applications, ranging from the production of simple replica key chains to complicated geometric parts for the aerospace industry [2]. 3D printing technology is mainly utilised in the healthcare [3], electrical [4], automotive [5], aerospace [6] and construction industries [7]. It was started in the 1980s by Charles Hull and 3D printing technology has since developed rapidly. Presently, a wide range of materials can be printed using this technology [8].

There are many types of $3 \mathrm{D}$ printing techniques currently available in the market, for instance, fused deposition modelling (FDM), selective laser sintering (SLS), stereo lithography (SLA), direct metal laser sintering (DMLS), poly Jet, multi jet fusion (MJF), digital light processing (DLP), binder jetting (BJ), electron beam melting (EBM), continuous liquid interphase printing (CLIP), selective deposits layer (SDL) and laminated object manufacturing (LOM).

Figure 1 shows the statistics for the adoption of 3D printing technology [9]. These statistics are based on interviews with 1,000 respondents distributed globally. The respondents were from ten industries, namely the automotive, aeronautics and aerospace, consumer goods, education, electrical and electronics, healthcare, high technology, industrial goods, mechanics and metals, and services. According to Sculpteo's 4th annual report on 3D Printing and Digital Manufacturing 2018, the most frequently used $3 \mathrm{D}$ printing technology is Fused Deposition Machine (FDM) [9].

In 2018, $46 \%$ of participants were found to have used the FDM technology, which represents an increase of $10 \%$ compared to 2017. Moreover, Direct Metal Laser Sintering (DMLS) technology exhibited strong growth from $8 \%$ in 2017 to $21 \%$ in 2018 , nearly triple in increase. This was because DMLS is able to print metal products with complex geometry and design [9].

In this paper, Critical Success Factors (CSFs) that influence the implementation of 3D printing technology in the manufacturing industry are discussed thoroughly. This paper is expected to help governments, researchers, practitioners and consultants to gain a better understanding of factors that affect the successful adoption of 3D printing technology in the manufacturing industry.

\section{METHODOLOGY}

This study was conducted by searching the Internet, specifically the SCOPUS database, using a combination of keywords or terms such as "3D printing" or "Additive Manufacturing (AM)". SCOPUS is a major database that compiles citations and abstracts from peer-reviewed conference proceedings, books and scientific journals. The database delivers a comprehensive overview of the world's research output in the fields of art, biomedical, humanity, science, social science and technology. Then, the study identified relevant journals and classified it according to those dealing with the implementation of $3 \mathrm{D}$ 


\section{D-PRINTING TECHNOLOGIES}

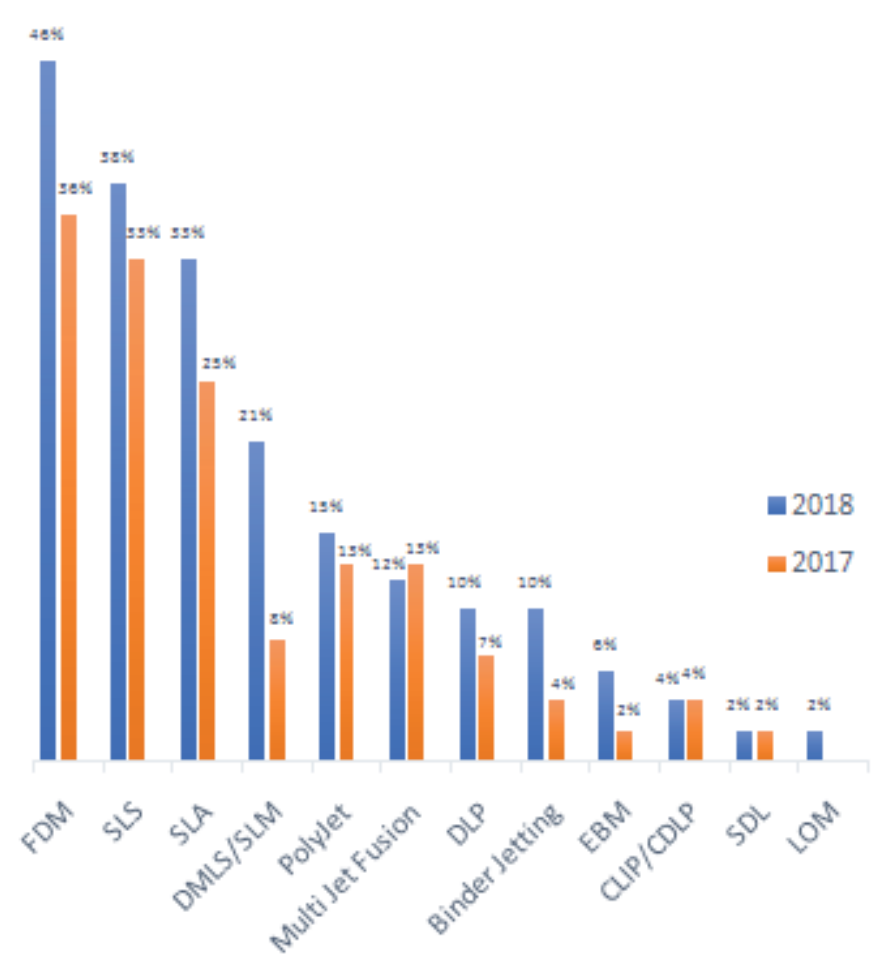

Figure 1: Statistic on the adoption of $3 D$ printing technology [9]

printing technology and lastly, determine the CSFs that affect the implementation of 3D printing technology in manufacturing firms.

\section{CRITICAL SUCCESS FACTORS (CSFS)}

Critical Success Factors (CSFs) are related to the specifics of an organisation's situation. This method certainly differs from industry to industry depending on the organization's specialty. To sum it up, CSFs are limited areas where a suitable result will ensure the successful performance of an industry, branch or individual. CSFs are key areas that entail greater attention in order to improve the organisation's performance and achieve managerial goals. [10].

The summary of CSFs for implementing 3D printing technology in manufacturing firms is created based on the literature review. The CSFs include cost, technology, business and support, management and organisation, materials, quality and accuracy, customer demand, the environment, and lastly, research and development.

\section{Cost}

By using 3D printing technology in the manufacturing industry, the company can reduce overall costs and this allows the company to optimise the production of $3 \mathrm{D}$ printed parts. Cost is an amount that must be incurred or paid to obtain something. To run a business, cost is an approximation of effort, materials, time, resources, utilities, risks and methods to deliver goods or services.
According to Singh and Raghav [11], implementation of a rapid expanding technology, like 3D printing technology, is affected by cost factors such as production costs. 3D printing technology is device-free and uses computer tools. In addition, the setup cost for a 3D printer is much cheaper than conventional setups. Therefore, production costs could be significantly reduced [15]. Generally, the $3 \mathrm{D}$ printer is driven by a computer installed with high dimensional and accurate processing software, thus, it is able to process directly from 3D designs using software, such as AutoCAD, Blender or Rhino 3D [11].

Meanwhile, according to Yeh and Chen [12], cost is one of the CSFs involved in the adoption of 3D printing technology. Cost is calculated based on several factors, such as usage, fixed cost of printing, and technology maintenance. In addition, the adoption of 3D printing is related to various types of investments, such as investments in software, tools, and system amalgamation [12].

Additionally, Schniederjans [13] stated that initial investment affects the successful implementation of 3D printing technology. 3D printing usage is growing rapidly and becoming more widespread in automobile, aviation and medical applications. According to Boon and Wee [14], these days, the price of 3D printers from RepRap, MakerBot or Ultimaker are very cheap and affordable. On the other hand, Awad et al., [15] mentioned that the price of a $3 \mathrm{D}$ printer depends on the type of the printer. The range of $3 D$ printer machines are from $£ 1500-£ 4250$ 000 [15].

In conclusion, there are numerous sub factors that affect the cost factor when effectively implementing 3D printing technology in the manufacturing industry. For example, production costs, fixed costs, usage costs, costs for technological maintenance and initial investment.

\section{Technology}

Chan et al., [16] stated that the main factor affecting adoption of 3D printing technology is the technology factor, for example the time taken to produce a product and the types of 3D printing technology. By using this technology, the time taken to manufacture a product can be reduced, especially customised products. Even though there are various types of $3 D$ printers, the steps for producing 3D printed products are similar to each other. After receiving the actual sample from buyers, the manufacturer can scan it by using a 3D scanner and then print it out. It will be easier and faster if buyers can prepare their own design and just provide the electronic file. Moreover, by applying 3D printing technology, customers can anytime modify the sample design, and they can get the revised product design in a short time. Furthermore, it was found that the fabricating process in 3D printing technology is another success factor that warrants the adoption of 3D printing technology in the manufacturing industry. 3D printing technology provides a fast and efficient manufacturing process of products for the customers. At the same time, no tooling is required to produce 
a $3 \mathrm{D}$ product that significantly reduces the processing ramp-up time [16].

Attaran [17] agreed with Chan et al., [16], by saying that it takes hours to produce a prosthetics. Adding multiple printer heads with nozzles increases the speed of the 3D printing process and various materials can be used as printing materials at the same time [18].

Horst et al., [18] pointed out the importance of the technological factor in 3D printing technology. Today, manufacturing firms need intelligent and digitised processes to cope with contemporary industrial challenges and business opportunities. The manufacturing industry is currently undergoing transformation from mass production to customized production. The rapid development of 3D printing technology in the manufacturing industry can help increase productivity and customisation while maintaining the quality of the product. Undoubtedly, 3D printing technology is an alternative manufacturing process to cope with the current industrial revolution [18].

$3 \mathrm{D}$ printing has revolutionized the way manufacturing is carried out. There are several 3D printers that can build objects, such as Stereolithography (SLA), Fused Deposition Modelling (FDM), Selected Laser Sintering (SLS) and others. The type of 3D printer used depends on the object to be manufactured. For example, SLA provides an interesting compromise between resolution, material selection, speed and low surface roughness [19]. Meanwhile FDM is widely used in the prototyping and direct manufacture of parts using thermoplastic materials [20]. Furthermore, the SLS printer can minimise the wastage of materials and promote the recycling of feedstock. This is because SLS functions by utilising a laser beam that selectively sinters powder particles together, allowing the fabrication of highly crystalline structures [21].

In summary, there are numerous sub factors that affect the technological factor when trying to successfully adopt 3D printing technology in the manufacturing industry. It includes the process of 3D printing technology, type of machine and time taken to produce the printed object

\section{Business and support}

Business and support are some of the success factors required for the execution of $3 \mathrm{D}$ printing technology. According to Attaran [17], the appearance of 3D printing technology will have commercial implications and colossal social impact if not regulated effectively. With the growth in technology, manufacturers need tighter regulations and rules to protect the invention of products. Therefore, the performance of manufacturing firms that adopt this technology is significantly affected by business matters and support from the government in the form of regulations.

Schniederjans [13] stated that the main obstacle in $3 D$ printing technology in terms of business and support are regulatory and legal issues. According to studies, the government should improve legislation to protect the creator's intellectual property rights because in reality, the customer can collaborate with other companies to create clandestine market copies of the genuine product. Joshi and Sheikh [22] also pointed out that among the successful factors that influence the implementation of 3D printing technology are business and support factors, such as regulatory and certification requirements. Regulatory scrutiny is very important in areas where 3D printing technology can be adopted rapidly. Currently, despite ongoing intensive research, the adoption of $3 \mathrm{D}$ printing technology by the aerospace industry is still low. This is because aerospace applications require stringent certification that is paramount to the safety of airspace and aircrafts. Safety standards and testing of 3D printing technology in the aeronautics industry is still under development. Therefore, the certification requirement is a very important sub dimension that enables the successful acceptance of 3D printing technology.

In conclusion, there are numerous sub factors that affect business and support factors for the successful implementation of 3D printing technology, such as government support, global support and regulatory aspects.

\section{Management and Organisation}

According to Chan et al., [16], the acceptance of 3D printing technology in the manufacturing industry is influenced by management and organisational factors, such as the flow of the supply chain and the size of the company. 3D printed objects are printed using a single process instead of several processes that could involve different supply chains. It will change the industrial technique, which then modifies the supply chain network and increases its efficiency. Conversely, there are challenges when adopting 3D printing technology in a different type of manufacturing industry. Furthermore, Chan et al., [16] also said, it would be more feasible to use 3D printing technology for small production capacities, especially when there is uncertain demand [16].

Apart from that, Kretzschmar et al., [23] found that the adoption of 3D printing is associated with management and organisational factors, such as the supply chain and workers' knowledge and skills. A new incentive to re-evaluate current supply chain models will lead to a change in the distribution and manufacturing scenes. The supply chain related to 3D printing technology presents a major change in cost for industrial components. In addition, workers' knowledge and skills also play a fundamental role in the successful implementation of 3D printing. Hence, the company should hire workers with advanced skills [23].

Furthermore, according to Sandström [24], highly skilled technicians are required in the hearing aid industry to handle 3D printing technology. This is because, the technician's work is a work of art and there is no room for human error or any guarantee of an accurate 3D product. Therefore, the worker should possess good skills and knowledge required for using computer-aided design (CAD), excellent soft skills and critical thinking to solve 
problems and create the new designs [24].

In a nutshell, there are numerous sub factors that affect management and organisational factors leading to the successful implementation of 3D printing technology, such as the flow of the supply chain, size of the company as well as workers' knowledge and skills. Materials are another success factor in the adoption of 3D printing technology related to the manufacturing industry. The materials used in printing the 3D object is strongly dependent on the resolution of the printer, printing process, as well as the similarity and suitability of the products. The materials must be selected and refined according to the purpose or application of the products. Various choices of printing technology, a wide range of materials ranging from flexible to rigid and from coloured to transparent are available for printing the product in only one step [25].

According to Boetker et al., [26], the company needs to determine suitable materials that can match the flow properties required for adjusting the nozzle temperature or speed of 3D printing. There are certain materials whose properties are highly sensitive [23]. For example, resin [27], hydroxyl apatite (HAp) [28], chitosan-calcium phosphate [29], titanium [30], lithium iron [31] and so on.

In the meantime, Zhang et al., [32] pointed out that materials have an overbearing influence that affects the adoption of 3D printing technology. For example, the fabrication of Electrochemical Energy Storage devices faces difficulties in obtaining suitable materials for producing printed energy storage. Presently, the production of electrodes using 3D printing technology requires materials that are limited in supply compared to materials used in conventional processes. Therefore, the choice of materials is one of the main sub factors of $3 \mathrm{D}$ printing technology.

Furthermore, Wu et al., [33] mentioned that nowadays, the price of $3 D$ printing materials for surgical plans has decreased, but the cost of equipment and staff should be considered if employing 3D printing technology [33].

It can be concluded that there are numerous sub factors, such as choice and price of materials, that affect the material aspect for the positive application of 3D printing technology.

\section{Quality and accuracy}

Schniederjans [13] showed that the execution of 3D printing technology in the manufacturing industry was influenced by quality factors, such as the surface of the product. The manufacturer is responsible for making appreciable products. For example, 3D printed food utensils contain empty spaces where bacteria can easily grow.

Besides that, Kretzschmar et al., [23] pointed out that quality and accuracy are important factors for implement $3 \mathrm{D}$ printing technology. The quality of $3 \mathrm{D}$ printed objects is expected to be enhanced by using 3D printing technology and can increase the mechanical properties of prod- ucts. According to Zeng et al., [34], hydroxyapatite (HAp) has poor mechanical properties and cannot be used in load-bearing implants. However, by using the Digital Light Processing (DLP) machine, the results showed HAp was suitable for DLP 3D printing technology and could form HAp ceramic parts with excellent biocompatibility and compressive properties [34].

Meanwhile, Wang et al., [35] mentioned that the type of machine also played an important role in implementing 3D printing technology. For example, the result for producing Surimi food by using 3D printing technology had shown that the nozzle height, nozzle diameter, nozzle movement speed and extrusion rate are also critical process parameters influencing the geometry accuracy of the 3D Surimi printing [35].

3D printing technology also needs to fulfil the accuracy and tolerance requirements of a product. To fulfil the quality and accuracy levels, 3D printing technology is influenced by several sub factors, such as type of machine and required surface roughness.

In a nutshell, there are many subfactors that affect the quality and accuracy of factors in the successful execution of 3D printing technology, such as the type of surface required.

\section{Demand}

Based on this study, the successful adoption of 3D printing technology is also affected by aspects of demand, like market trends. In the manufacturing market, the market share of additive manufacturing is less than $2 \%$. This shows that many firms still struggle to adopt $3 D$ printing technology in their manufacturing processes [8]. According to Boon and Wee [14], the most influencing factor in the implementation of $3 \mathrm{D}$ printing technology is customer demand. 3D printing technology is important and plays an important role in designing and manufacturing specialized products.

In conclusion, there are many sub factors that affect the demand factor in the successful adoption of 3D printing technology, such as market trends.

\section{Environment}

Holzmann et al., [8] pointed out that the adoption of 3D printing technology is also affected by environmental factors, such as being environmental friendly to users and manufacturers. 3D printing technology greatly affects the environmental friendly because it can reduce the amount of waste produced as well as the amount of raw materials needed for the process.

Meanwhile, Sreehitha [36] stated that the adoption of 3D printing technology affects the environment, such as the environmental friendly user. The automotive industry is a respectable example of how 3D printing technology drives productivity and efficiency from the design stage to the manufacturing stage. Nowadays, the manufacturing firm can print a part of a component by using 3D 
printing processes and at the same time generate less waste and save resources.

Lastly, the minimal consumption of processing energy for using 3D printing technology can lead to improvements in sustainability efforts. Therefore, energy consumption is the subdimension for the environmental factor [37].

In summary, there are many subfactors that affect the environmental factor, which influences the successful adoption of $3 \mathrm{D}$ printing technology by manufacturing firms. It includes being environmentally friendly, sustainable and implicating a reduction in energy consumption.

\section{Research and Development}

In line with Attaran's [17] research, the implementation of rapid technologies, like 3D printing technology, is affected by research and development factors, such as the innovation of the 3D printer. Thus, to be more functional, $3 \mathrm{D}$ printers must shift to the other side of the current focus of providing 3D printing technology. Innovation must take on overall $3 \mathrm{D}$ printing performance. The printer must become autonomous, more reliable, easier to use and faster.

Software also contributes to the successful implementation of rapid prototyping technology. As stated by Hager et al., [38], the software is a factor that ensures interoperability of the application used at the printing development, architectural design and organisational analysis stages. In order to systematise the optimization process and its management, transformation of the electronic product and confirmation of its suitability for the printing process must be achieved by going through fully automatic processes. Therefore, research and development factors are one dimension of success factors that influences the implementation of $3 D$ printing technology in

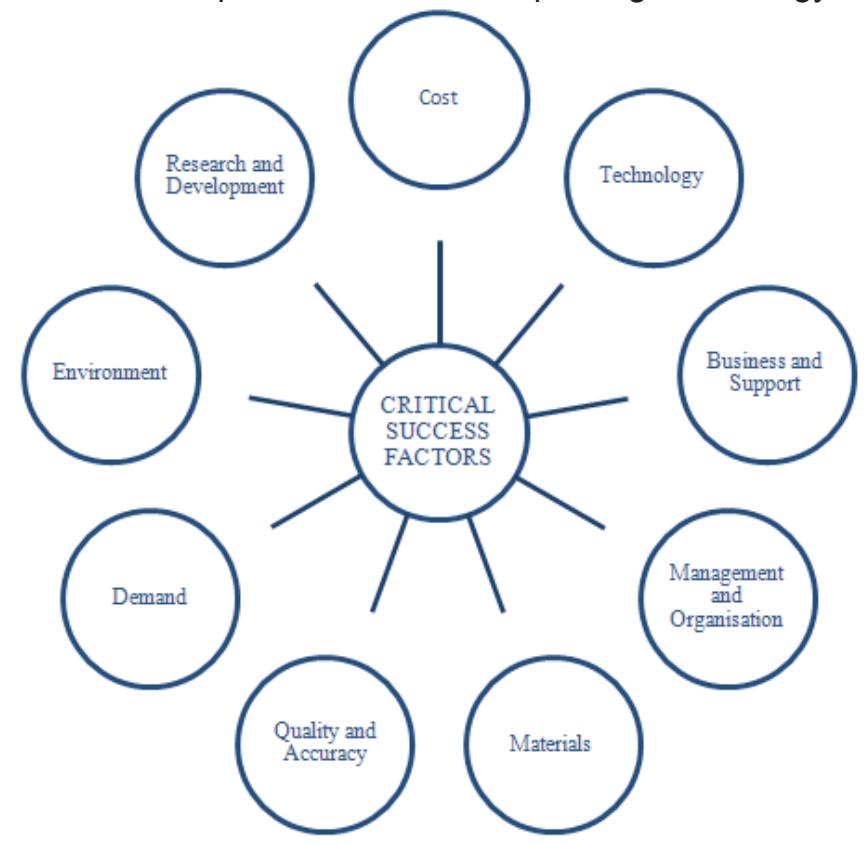

Figure 2: Summary of critical success factors (CSFs) for 3D printing technology in manufacturing firms the manufacturing industry [38]. Figure 2 shows the summary of Critical Success Factors (CSFs) for 3D printing technology in manufacturing firms.

\section{CONCLUSION}

In this review, there are many Critical Success Factors (CSFs) associated with the adoption of 3D printing technology in the manufacturing industry. In conclusion, based on previous studies, management and organisation as well as technology are major issues that influence the implementation of 3D printing technology in the manufacturing industry. $3 \mathrm{D}$ printing technology is a market niche with an enormous improvement potential if the organisation has knowledge and information about the CSFs associated with the adoption of 3D printing technology. More information regarding the CSFs that could influence the successful adoption of 3D printing technology in Malaysia will help businesses and the government to upgrade and improve 3D printing technology infrastructure. Thus, this review aims to help identify the CSFs that could influence the successful adoption of 3D printing technology by manufacturing firms.

It is recommended that field observations and document reviews are conducted by future studies by using qualitative and quantitative methods. Triangulation is the best method to enhance the validity or reliability of a qualitative research. By using the triangulation method, it can enhance the accuracy of data interpretation as well as obtain multiple sources of data. Lastly, future studies can focus on specific industries, such as automotive, architecture, biomedical, education and military. A more thorough study can be conducted to obtain more detailed information on this 3D printing technology.

\section{ACKNOWLEDGMENT}

The working paper was sponsored by Universiti Tun Hussein Onn, Malaysia and the Ministry ofEducation Malaysia through Research Grant Scheme, TIER 1 Vot U880.

\section{REFERENCES}

1. Markstedt, K., Håkansson, K., Toriz, G \& Gatenholm, P. (2019). Materials from trees assembled by 3D printing - Wood tissue beyond nature limits. Appl. Mater. Today, vol. 15, pp. 280-285.

2. Jakus, A. E. (2019). An Introduction to 3D Printin-Past, Present, and Future Promise. In 3D Printing in Orthopaedic Surgery. (pp. 1-15). Elsevier BV. doi:10.1016/b978-0-323-58118-9.00001-4

3. Bhushan, J., \& Grover, V. (2019). Additive Manufacturing: Current Concepts, Methods, and Applications in Oral Health Care. In C. Prakash, S. Singh, R. Singh, S. Ramakrishna, B.S. Pabla, S. Puri, \& M.S. Uddin (Eds.), Biomanufacturing. (pp. 103-122). Cham: Springer Science and Business Media LLC. doi:10.1007/978-3-030-13951-3_5 
4. Pumera, M. (2019). 3D printed electrochemical systems for biomedical analytical applications. Curr. Opin. Electrochem.

5. Daly, A., Lu, J., \& Heemsbergen, L. (2019). Another Dimension of Digital: 3D Printing and Intellectual Property in Asia 1. SSRN, vol. 1, no. 1, pp. 1-14.

6. Najmon, J. C., Raeisi, S., \& Tovar, A. (2019). Review of additive manufacturing technologies and applications in the aerospace industry. In Additive Manufacturing for the Aerospace Industry. (pp. 7-31). Elsevier BV. doi:10.1016/b978-0-12-814062-8.00002-9

7. Holt, C., Edwards, L., Keyte, L., Moghaddam, F., \& Townsend, B. (2019). Construction 3D Printing. In 3D Concrete Printing Technology. (pp. 349-370). Elsevier BV. doi:10.1016/b978-0-12-815481-6.000178

8. Holzmann, P., Schwarz, E. J., \& Audretsch, D. B. (2018). Understanding the determinants of novel technology adoption among teachers: the case of 3D printing. Journal of Technology Transfer, vol. 1, no. 33, pp. 1-9.

9. Zeijderveld, J. V. (2018). State of 3D Printing 2018: The rise of metal 3D printing, DMLS, and finishes. Sculpteo. [Online]. Available: https://www.sculpteo. com/blog/2018/06/12/state-of-3d-printing-2018-therise-of-metal-3d-printing-dmls-and-finishes/.

10. Bullen, C. V., \& Rockart, J. F. (1981). A primer on critical success factors. Working Paper (Sloan School. Management), no. 69, pp. 1-64.

11. Singh, P., \& Raghav, A. (2018). 3D Food Printing : A Revolution in Food Technology. Acta Science Nutrient Health, vol. 2, no. 2, pp. 11-12.

12. Yeh, C. C., \& Chen, Y. F. (2018). Critical success factors for adoption of 3D printing. Technology Forecasting and Social Change, vol. 132, no. 2018, pp. 209-216.

13. Schniederjans, D. G. (2017). Adoption of 3D-printing technologies in manufacturing: A survey analysis. International Journal Production Economics, vol. 183, no. 2017, pp. 287-298.

14. Boon, W., \& Wee, B. V. (2018). Influence of 3D printing on transport: a theory and experts judgment based conceptual model. Transportation Review, vol. 38, no. 5, pp. 556-575.

15. Awad, A., Trenfield, S. J., Goyanes, A., Gaisford, S., \& Basit, A. W. (2018). Reshaping drug development using 3D printing. Drug Discovery Today, vol. 23, no. 8, pp. 1547-1555.

16. Chan, H. K., Griffin, J., Lim, J. J., Zeng, F., \& Chiu, A. S. F. (2018). The impact of 3D Printing Technology on the supply chain: Manufacturing and legal perspectives. International Journal of Production Economics, vol. 205, no. 2018, pp. 156-162.
17. Attaran, M. (2017). The rise of 3-D printing: The advantages of additive manufacturing over traditional manufacturing. Business Horizon, vol. 60, no. 5, pp. 677-688.

18. Horst, D. J., Duvoisin, C. A., \& Vieira, R. D. A. (2018). Additive Manufacturing at Industry 4.0: a Review. International Journal of Engineering and Technical Research, vol. 8, no. 8, p. 2454-4698.

19. Juskova, P., Ollitrault, A., Serra, M., Viovy, J. L., \& Malaquin, L. (2018). Resolution improvement of 3D stereo-lithography through the direct laser trajectory programming: Application to microfluidic deterministic lateral displacement device," Analytica Chimica Acta, vol. 1000, pp. 239-247.

20. Armillotta, A. (2019). Simulation of edge quality in fused deposition modeling. Rapid Prototyping Journal, vol. 25, no. 3, pp. 541-554.

21. Fina, F., Goyanes, A., Madla, C. M., Awad, A., Trenfield, S. J., Kuek, J. M., Patel, P., Gaisford, S., \& Basit, A. W. (2018). 3D printing of drug-loaded gyroid lattices using selective laser sintering. International Journal of Pharmaceutics, vol. 547, no. 1-2, pp. 44-52.

22. Joshi, S. C., \& Sheikh, A. A. (2015). 3D printing in aerospace and its long-term sustainability. Virtual Physical. Prototyping, vol. 10, no. 4, pp. 175-185.

23. Kretzschmar, N., Chekurov, S., Salmi, M., \& Tuomi, J. (2018). Evaluating the Readiness Level of Additively Manufactured Digital Spare Parts: An Industrial Perspective. Applied Sciences, vol. 8, no. 10, p. 1837.

24. Sandström, C. G. (2016). The non-disruptive emergence of an ecosystem for 3D Printing - Insights from the hearing aid industry's transition. Technological Forecasting Social Change, vol. 102, no. 2016, pp. 160-168.

25. Yap, Y. L., Tan, Y. S. E., Tan, H. K. J., Peh, Z. K., Low, X. Y., Yeong, W. Y., Tan, C. S. H., \& Laude, A. (2017). 3D printed bio-models for medical applications. Rapid Prototyping Journal, vol. 23, no. 2, pp. 227-235.

26. Boetker, J., Water, J. J., Aho, J., Arnfast, L., Bohr, A., \& Rantanen, J. (2016). Modifying release characteristics from 3D printed drug-eluting products. European Journal of Pharmaceutical Sciences, vol. 90, no. 2016, pp. 47-52.

27. Mousawi, A. A., Garra, P., Sallenave, X., Dumur, F., Toufaily, J., Hamieh, T., Graff, B., Gigmes, D., Fouassier, J. P., \& Laleeve, J. (2018). п-Conjugated Dithienophosphole Derivatives as High Performance Photoinitiators for 3D Printing Resins. Macromolecules, vol. 51, no. 5, pp. 1811-1821.

28. Li, Q., Lei, X., Wang, X., Cai, Z., Lyu, P., \& Zhang, G. (2019). Hydroxyapatite /Collagen 3D printed Scaffolds and their Osteogenic Effects on hBMSCs. Tissue Engineering, pp. 1-62, 2019 
29. Caballero, S. S. R., Saiz, E., Montemboult, A., Tadier, S., Maire, E., David, L., Delair, T., \& Gremillard, L. (2019). 3-D printing of chitosan-calcium phosphate inks: rheology, interactions and characterization. Journal of Materials Science: Materials in Medicine, vol. 30, no. 1, pp. 1-15.

30. Li, Z., Liu, C., Wang, B., Wang, C., Wang, Z., Yang, F., Gao, C., Liu, H., Qin, Y., \& Wang, J. (2018). Heat treatment effect on the mechanical properties, roughness and bone ingrowth capacity of 3D printing porous titanium alloy. RSC Advances., vol. 8, no. 22, pp. 12471-12483.

31. Ben-Barak, I., Kamir, Y., Menkin, S., Goor, M., Skehtman, I., Ripenbein, T., Galun, E., Golodnitsky, D., \& Peled, E. (2018). Drop-on-Demand 3D Printing of Lithium Iron Phosphate Cathodes. Journal of The Electrochemical Society, vol. 166, no. 3, pp. A5059A5064.

32. Zhang, F., Wei, M., Viswanathan, V. V., Swart, B., Shao, Y., Wu, G., \& Zhou, C. (2017). 3D printing technologies for electrochemical energy storage. Nano Energy, vol. 40, no. 2017, pp. 418-431.

33. Wu, A. M., Lin, J. L., Kwan, K. Y. H., Wang, X. Y., \& Zhao, J. (2018). 3D-printing techniques in spine surgery: the future prospects and current challenges. Expert Review of Medical Devices, vol. 15, no. 6, pp. 399-401.
34. Zeng, Y., Yan, Y., Yan, H., Liu, C., Li, P., Dong, P., Zhao, Y., \& Chen, J. (2018). 3D printing of hydroxyapatite scaffolds with good mechanical and biocompatible properties by digital light processing, Journal of Materials Science, vol. 53, no. 9, pp. 6291-6301.

35. Wang, L., Zhang, M., Bhandari, B., \& Yang, C. (2018). Investigation on fish surimi gel as promising food material for 3D printing. Journal of Food Engineering, vol. 220, pp. 101-108.

36. Sreehitha, V. (2017). Impact of 3D Printing in Automotive Industries. International Journal of Mechanical and Production Engineering, vol. 5, no. 2, pp. 1-5.

37. Samuel, F. W. (2017). 3D printing and supply chain management: A literature review and research agenda. International Conference on Mechanical Engineering (Meche), vol. 2, no. 1, pp. 1-12.

38. Hager, I., Golonka, A., \& Putanowicz, R. (2016). 3D Printing of Buildings and Building Components as the Future of Sustainable Construction? Procedia Engineering, vol. 151, no. 2016, pp. 292-299. 